\title{
Meat Analogue Derived from Common Legumes
}

\author{
Dolly P. Maroma \\ College of Industrial Technology, Bulacan State University, Bulacan, Philippines \\ Email: maromadolly@ymail.com
}

Received 7 January 2015; accepted 22 January 2015; published 27 January 2015

Copyright (C) 2015 by author and OALib.

This work is licensed under the Creative Commons Attribution International License (CC BY). http://creativecommons.org/licenses/by/4.0/

\section{Abstract}

This research study aimed to explore the possibility of utilization of other common legumes i.e. white kidney beans and lima beans that can mimic the texture and taste of natural meat counterpart and to establish recommendations for other legumes as a considerable raw material substitute in production of texturized vegetable protein (TVP) that can simulate natural meat in terms of organoleptic properties that comprise equivalent ingredient functions as soybean based meat analogues. The meat analogue from common legumes was developed using the combination of indigenous legumes, which are commonly available all seasons, such as cannellini, lima and white kidney beans. Based on the microbiological analysis, the Aerobic Plate Count of the product has an actual value of less than $10^{4} \mathrm{cfus} / \mathrm{g}$ sample, the Psychotropic count accounts to less than $10^{3} \mathrm{cfus} / \mathrm{g}$ sample, the Coliform count with an actual value of less than $10^{2} \mathrm{cfus} / \mathrm{g}$ sample, Yeast and Molds count of less than 10 cfus/g sample, E. coli Count with an actual value of less than 10 cfus/g sample and negative findings for Salmonella Determination. In terms of acceptability of the product, the appearance, aroma and texture got a mean score of 7 which is interpreted as moderately based on the hedonic rating scaling. The taste or flavor attribute got a mean score of 8 which is interpreted as very much and 7.35 for overall acceptability which is interpreted as moderately as well. The product passed the BFAD standards in terms of microbiological analysis. The product passed the evaluation for overall acceptability.

\section{Keywords}

Meat Analogue, Legumes, Textured Vegetable Protein (TVP)

Subject Areas: Food Science, Technology

\section{Introduction}

Breakthrough innovation comes rapidly and cautiously to the food and beverage industry. Smart and modern

How to cite this paper: Maroma, D.P. (2015) Meat Analogue Derived from Common Legumes. Open Access Library Journal, 2: e1249. http://dx.doi.org/10.4236/oalib.1101249 
ingredients are now in trend and widely applied in all areas of manufacturing in various purposes, like to make food behave in a certain way, as an alternative ingredient and to add or improve nutritional content of food products. One of these innovations is focusing into new protein sources that do not involve animals, for economic reasons or for healthier approach on protein sources. The researcher took the opportunity of creating a concept wherein a study shall focus on other protein sources utilizing other legume types aside from soybean in manufacturing meat analogues or substitutes.

Food scientists are now creating meat alternatives that truly taste like-and have the same "mouth feel"their nature-made counterparts. All this innovation could be great news for all those people concerned about health problems related to overconsumption of fat, salt and cholesterol. There is also a need to look for new ways to raise nutrition in the poor world. Fortunately, there are thousands of plant proteins in the world, and many of them have yet to be explored for use in the production of meat alternatives. Current investigations of the world's vast array of plane proteins can fundamentally reshape our food supply for the better. The researcher is hopeful that we can begin to meet the demand for a protein-rich diet in a new way.

A meat analogue, also called a meat substitute, mock meat, faux meat or imitation meat, approximates certain aesthetic qualities, primarily texture, flavor and appearance and chemical characteristics of specific types of meat [1]. It is understood to mean a food made from non-meats, sometimes without other animal products, such as dairy. The market for meat imitations includes vegetarians, vegans, non-vegetarians seeking to reduce their meat consumption for health or ethical reasons, and people following religious dietary laws, such as Kashrut or Halal. Medical literature today supports the superiority of a vegetarian diet to one high in animal protein [2]. Hindu cuisine features the oldest known use of meat analogues. Generally, meat analogue is soy based or gluten based.

\section{General Objective}

This study aimed to utilize common legumes such as white kidney beans, cannellini and lima beans as meat analogue or meat substitute.

\section{Specific Objectives}

1) To determine the ingredients and processes required in the development of Meat Analogue derived from Common Legumes.

2) To determine the microbiological qualities of Meat Analogue derived from Common Legumes in terms of:

2.1) Aerobic Plate Count;

2.2) Psychotropic Count;

2.3) Coliform Count;

2.4) Yeast and Molds Count;

2.5) E. coli Count; and

2.6) Salmonella Determination.

3) To determine the acceptability of the product in terms of:

3.1) Appearance;

3.2) Aroma;

3.3) Texture; and

3.4) Flavor.

\section{Methods and Techniques of the Study}

The researcher performed observations on the trends in the food industry and how innovation can change the traditional way in production of ingredients for a more sustainable means of manufacturing of food [3]. The researcher, as being exposed in the different functional ingredients got the idea through observation and exploring the possibility of food innovation apart from the conventional existing raw materials.

The following are the steps involved in the production of the product:

\subsection{Sanitation}

Prior the production of Meat Analogue from Common Legumes, the researcher prepared and soaked all the tools 
to be used into $20 \mathrm{ml} / 1 \mathrm{~L}$ chlorine solution for 1 hour and air dry overnight. Mechanical equipment (i.e. food processor, oven, etc.) particularly food contact surfaces were also ensured to be cleaned and sanitized prior use as well as the whole working area. To prevent human contamination, the researcher wore proper laboratory attire (laboratory gown, hair net, face mask, and elastic hand gloves) and followed Current Good Manufacturing Procedures (cGMP) in producing the prototype material of the study.

\subsection{Selection and Preparation of Raw Materials}

The researcher purchased the needed raw materials from a reputable supermarket (SM Hypermarket located in Barangay Pagala, Dona Remedios Trinidad Highway, Baliuag, Bulacan, Philippines) which sell high quality products. Legumes used were stored, when bough, in dry state packed in 500 grams weight packages and contained in clean transparent polyethylene plastic containers. The packages were labeled with product name and description, as well as shelflife of 3 years was visibly identified in each package. The materials were purchased from a reputable leading supermarket.

\subsection{Production of Meat Analogue from Common Legumes}

Soak the legumes (White kidney beans: $1 \mathrm{~kg}$, Cannelini Beans: 500 grams, Lima Beans: 500 grams) in water for at least 18 hours in 1:2 proportion. For 2 kilograms of legumes, water needed for soaking is 4 liters. Remove from soaking with the use of strainer and rinse in running water for at least 2 minutes. Transfer washed legumes into the stock pot and filled it with 4 liters of water. Cover the pot prior setting for boiling. Cook the legumes for 3 hours with occasional stirring until softened and skins are detached from the flesh of the beans. Remove skins from the legumes. Chop the peeled legumes into the food processor until fine texture is achieved. Preheat oven to $170^{\circ} \mathrm{C}$. Spread the chopped legumes into wax paper lined trays in $0.3 \mathrm{~mm}$ thickness. Ensure even spreading thickness as possible. Dry into the oven for 45 minutes to one (1) hour or until completely dry. Chop the dried legumes into the food processor to desired size depending upon the intended food application. Let cool and pack into plastic containers immediately. Keep sealed until ready for consumption.

After two (2) hours of producing the experimental prototype of Meat Analogue from Common Legumes, the researcher submitted sample at the Bulacan State University (BulSU) Analytical Testing Laboratory for microbiological analysis of the product in terms of: Aerobic Plate Count, Psychotropic Count, Coliform Count, Yeast and Molds Count, E. Coli Count and Salmonella Determination.

No comparison was made of the results obtained from the experiments of the product with results from other types of meat analogue or results published by existing researches.

The product was then applied to Chopped Sizzling Milkfish (Sizzling Bangus) and was subjected for acceptability in terms of: flavor, aroma, texture, taste/flavor among the students and faculty members of the Bulacan State University school canteen. A total of sixty (60) respondents participated in the evaluation of the product.

Product Processing Procedure is shown in Figures 1-12.

Product Rehydration Procedures are presented in Figures 13-15 (Figure 16).

\section{Presentation, Analysis and Interpretation of Data}

\subsection{Ingredients and Process Used in the Production of Meat Analogue from Common Legumes}

The meat analogue from common legumes was developed using the combination of indigenous legumes and are commonly available all season such as cannellini (500 grams), lima (500 grams) and white kidney beans (1 kilogram). The researcher used purified water to sanitize all the tools and equipment to be used in the production, as well as the working area to prevent possible threats of food contamination on the process of developing the product.

The product was made by applying the techniques of soaking, cooking, peeling, chopping and drying the product. Initially, the raw materials were soaked in potable water for 18 hours and rinsed before applying heat through boiling. Upon achieving the desired tenderness of the legumes, the skins were removed to attain good texture on the finished product. The peeled legumes were chopped to fine consistency utilizing a high-speed food processor. After chopping, it was subjected to layering into trays and dried using conventional oven heat application until physically dry. Lastly, the dried meat analogue sheets were cut according to preferred size 


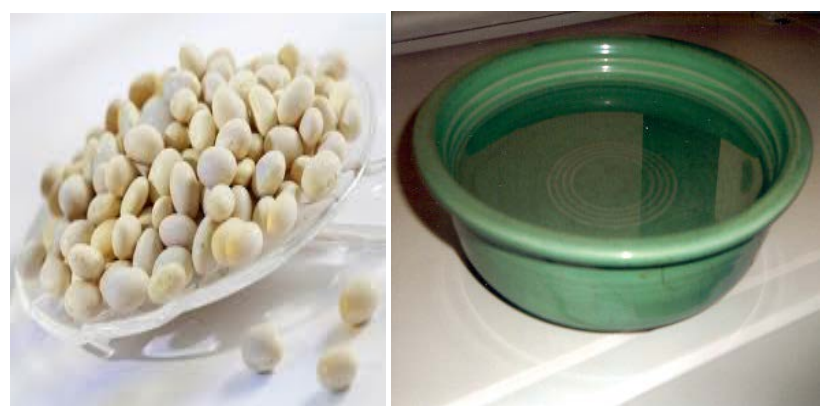

Figure 1. Mis-en-place.

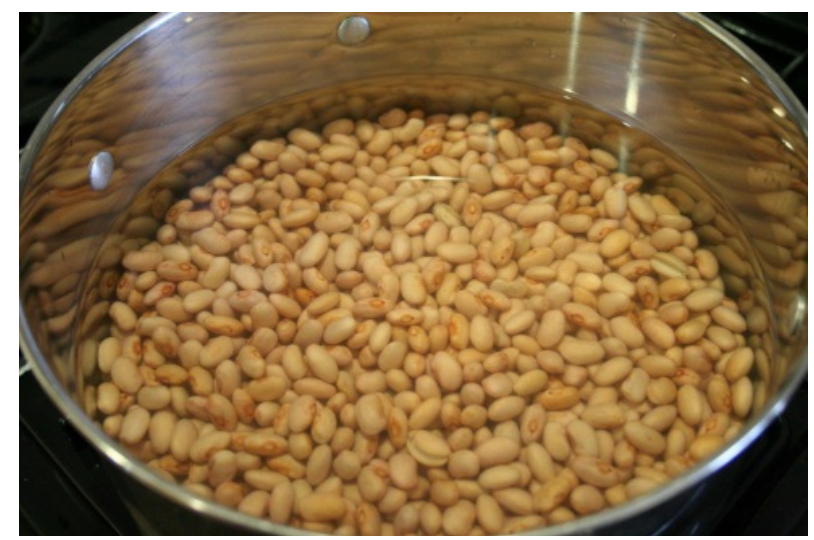

Figure 2. Soak the legumes in water for at least 18 hours in 1:2 proportion. For 2 kilograms of legumes, water needed for soaking is 4 liters.

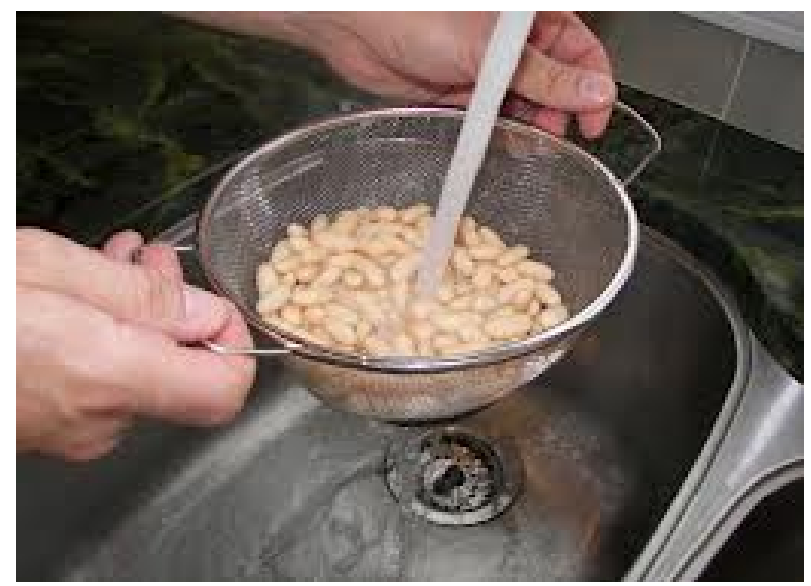

Figure 3. Soak the legumes in water for at least 18 hours in 1:2 proportion. For 2 kilograms of legumes, water needed for soaking is 4 liters.

based on the intended product application.

\subsection{Microbiological Analysis Results of Meat Analogue from Common Legumes}

The sample was subjected for microbiological analysis in terms of: Aerobic Plate Count, Psychotropic Count, Coliform Count, Yeast and Molds Count, E. coli Count and Salmonella Determination for Meat Analogue from Common Legumes. 


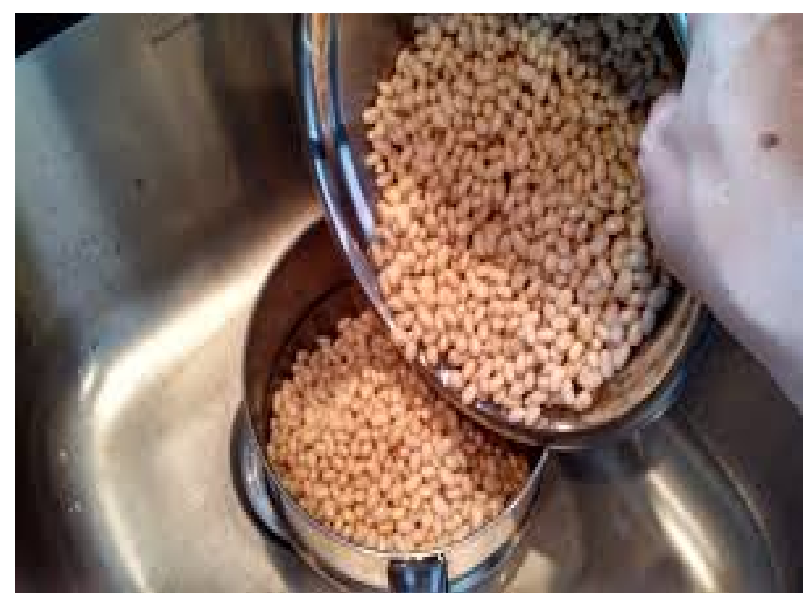

Figure 4. Transfer washed legumes into the stock pot and fill it with 4 liters of water. Cover the pot prior setting for boiling.

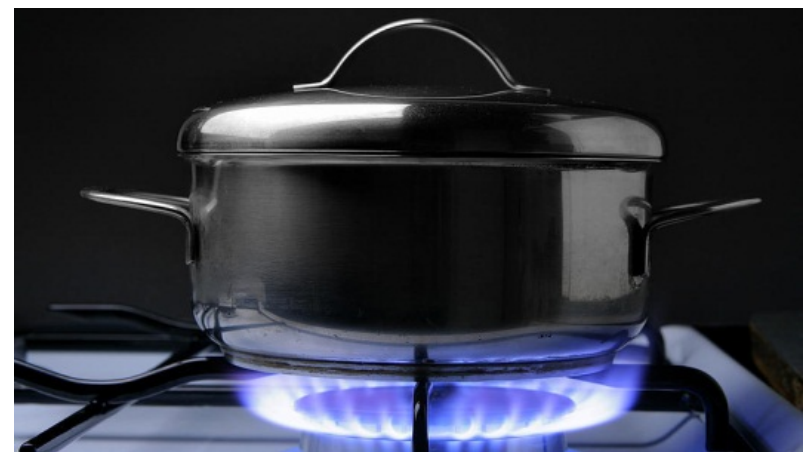

Figure 5. Cook the legumes for 3 hours with occasional stirring until softened and skins are detached from the flesh of the beans.

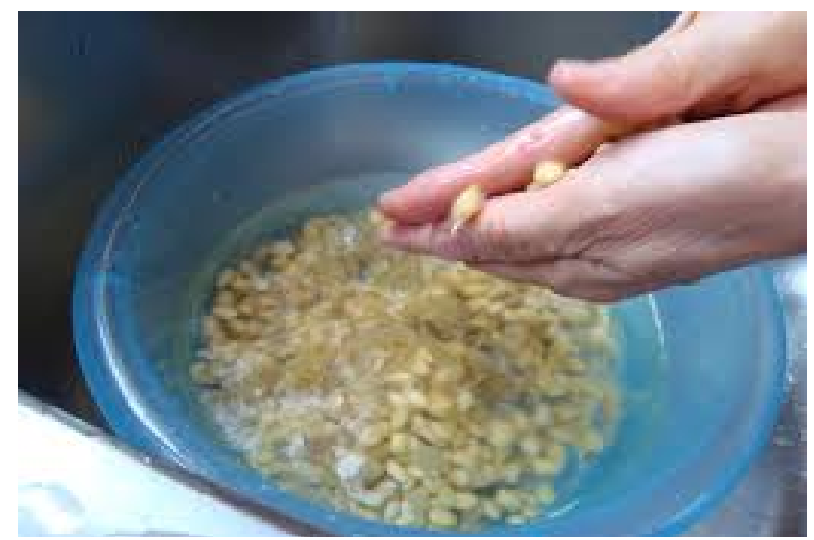

Figure 6. Remove skins from the legumes.

As presented on Table 1, the Aerobic Plate Count of the product has an actual value of less than $10^{4} \mathrm{cfus} / \mathrm{g}$ sample, the Psychotropic count accounts to less than $10^{3}$ cfus/g sample, the Coliform count with an actual value of less than $10^{2}$ cfus/g sample, Yeast and Molds count of less than 10 cfus/g sample, E. coli Count with an actual value of less than 10 cfus/g sample and a negative findings for Salmonella Determination. As stated on the interpretation of results conducted at the BulSU Analytical Testing Laboratory, the sample has count values that are within the BFAD Microbiological Standards. Sample was negative on the presence of Salmonella therefore 


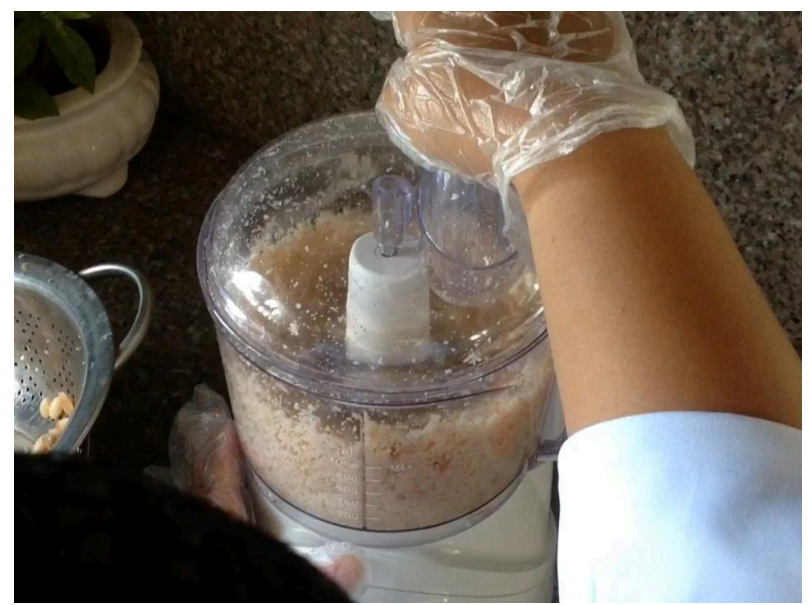

Figure 7. Chop the peeled legumes into the food processor until fine texture is achieved.

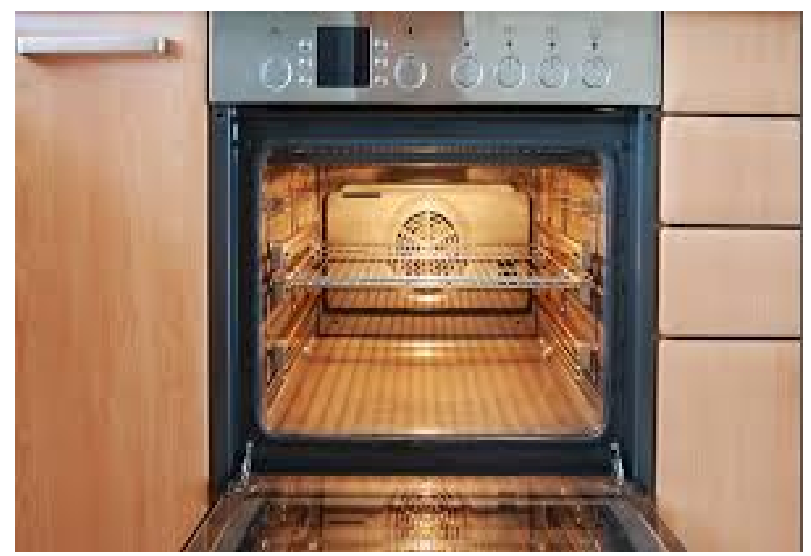

Figure 8. Preheat oven to $170^{\circ} \mathrm{C}$.

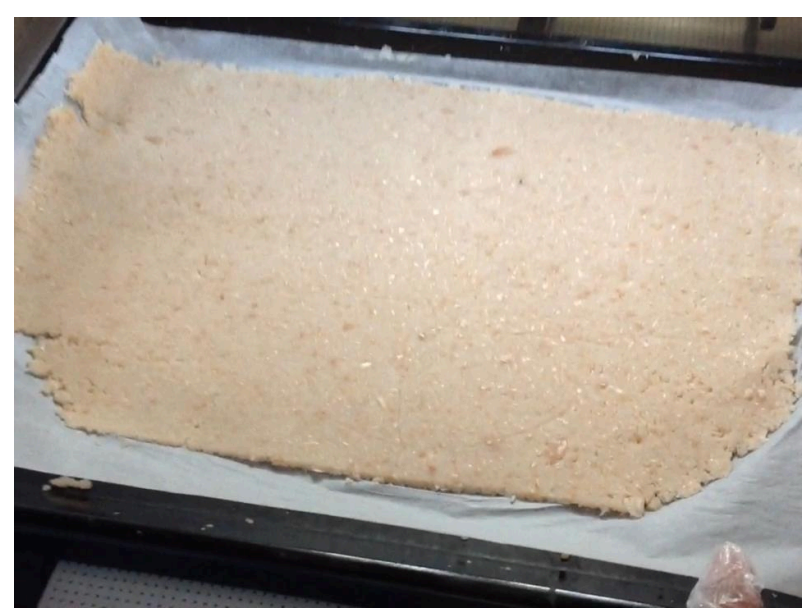

Figure 9. Spread the chopped legumes into wax paper lined trays in $0.3 \mathrm{~mm}$ thickness. Ensure even spreading thickness as possible.

it passed all the parameters of microbiological quality. Consequently, the product is considered safe for human consumption. The techniques and procedure applied were sufficient enough to control microbiological contami- 


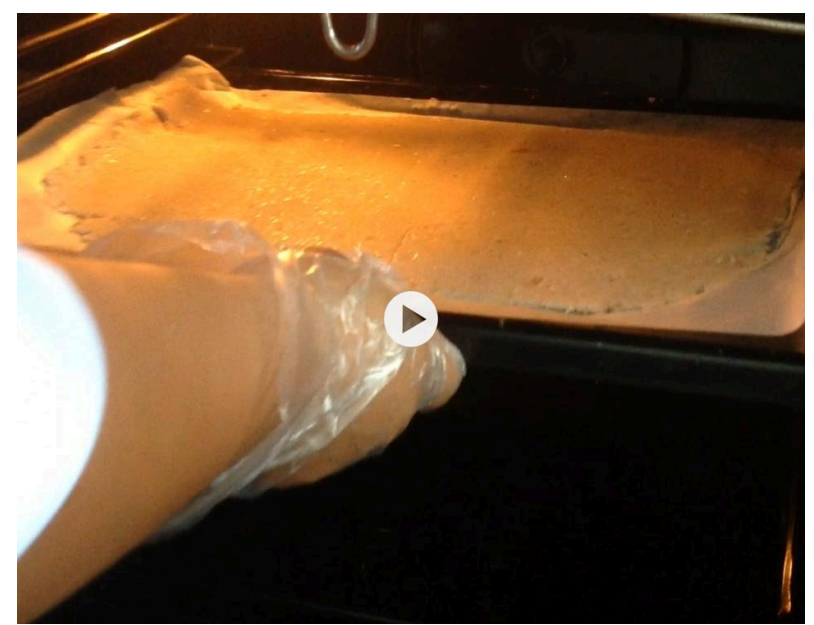

Figure 10. Dry into the oven for 45 minutes to 1 hour or until completely dry.

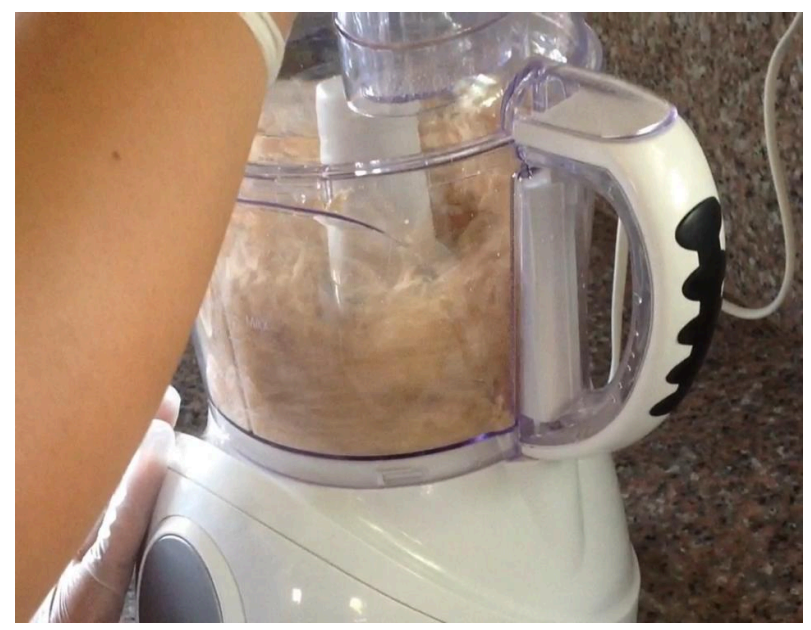

Figure 11. Chop the dried legumes into the food processor to desired size.

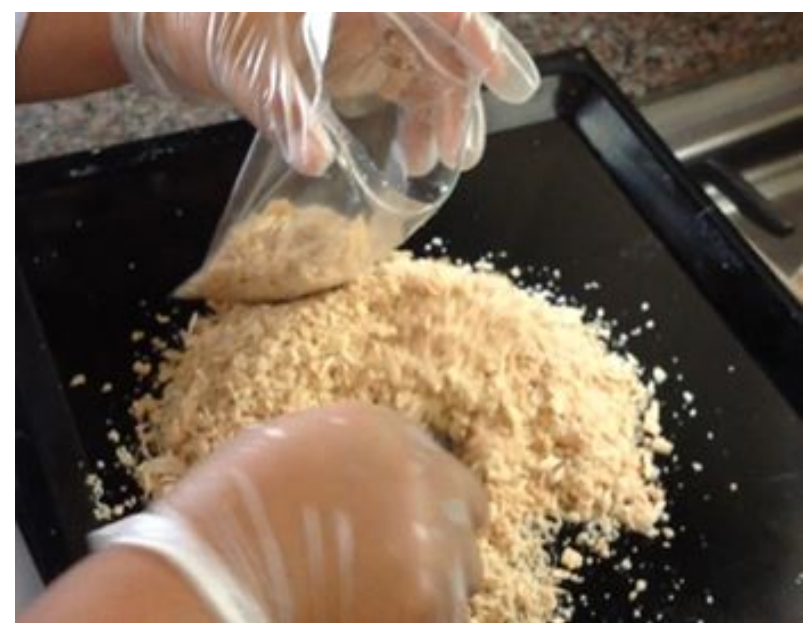

Figure 12. Let cool and pack into plastic containers immediately. Keep sealed until ready for consumption. 

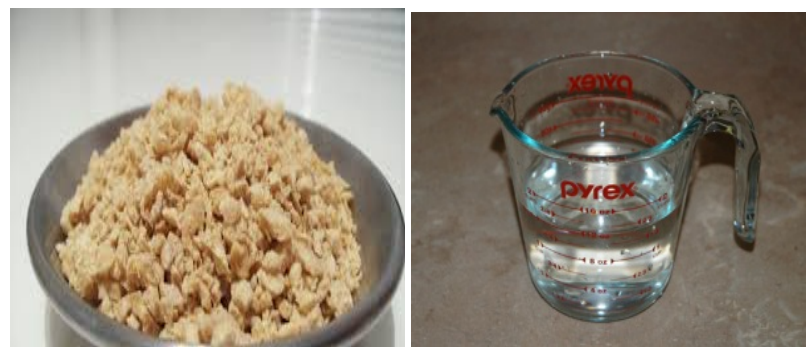

Figure 13. Rehydrating Proportion of meat analogue to hot water is $1: 3$. For every cup of dry meat analogue, add 3 cups of hot water $\left(80^{\circ} \mathrm{C}-90^{\circ} \mathrm{C}\right)$.

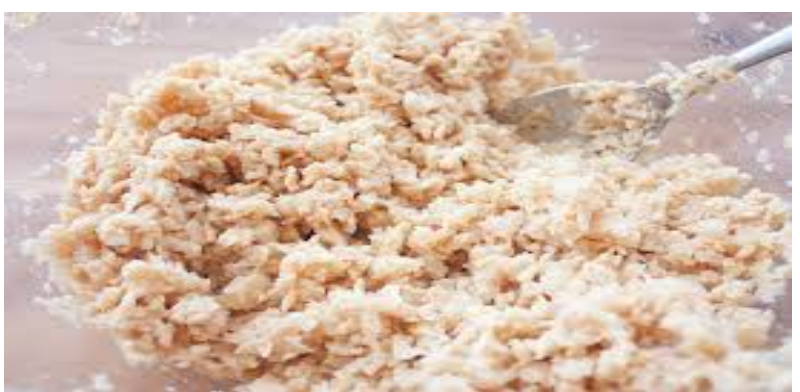

Figure 14. Hydrate for 3 - 5 minutes or until all liquids are completely absorbed. Yield: 4 cups of hydrated meat analogue.

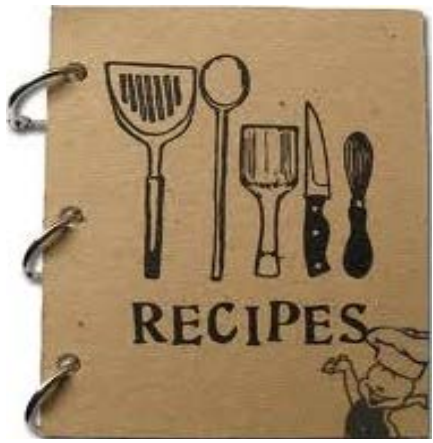

Figure 15. Add the meat analogue to your recipe of choice for healthier and more nutritious meals.

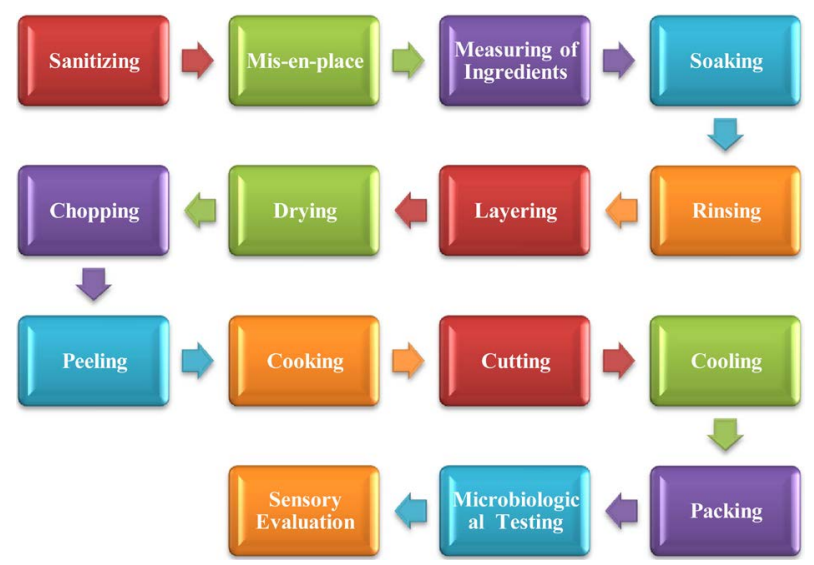

Figure 16. Flow chart of the study. 
Table 1. Microbiological analysis of meat analogue from legumes.

\begin{tabular}{clc}
\hline TESTS & ACTUAL VALUE & BFAD STANDARD VALUE \\
\hline Aerobic Plate Count & Less than $10^{4} \mathrm{cfus} / \mathrm{g}$ sample & Less than $10^{5} \mathrm{cfus} / \mathrm{g}$ sample \\
Psychotropic Count & Less than $10^{3} \mathrm{cfus} / \mathrm{g}$ sample & Less than $10^{4} \mathrm{cfus} / \mathrm{g}$ sample \\
Coliform Count & Less than $10^{2} \mathrm{cfus} / \mathrm{g}$ sample & Less than $10^{3} \mathrm{cfus} / \mathrm{g}$ sample \\
Yeast and Molds Count & Less than $10 \mathrm{cfus} / \mathrm{g}$ sample & Less than $10^{2} \mathrm{cfus} / \mathrm{g}$ sample \\
E. coli Count & Less than $10 \mathrm{cfus} / \mathrm{g}$ sample & Less than $10^{2} \mathrm{cfus} / \mathrm{g}$ sample \\
Salmonella Determination & Negative & Negative $(0 / 25 \mathrm{~g}$ sample $)$ \\
\hline
\end{tabular}

nation and prevent the growth of most organisms.

\subsection{Respondents of the Study}

The product was subjected to evaluation for acceptability in terms of: flavor, aroma, texture, taste/flavor among the students and faculty members of the Bulacan State University school canteen. A total of sixty (60) respondents participated in the evaluation of the product.

\begin{tabular}{ccc}
\hline Respondents & Age Range & Number \\
\hline Faculty & $25-57$ & 15 \\
Students & $16-21$ & 45 \\
Total & & $\mathbf{6 0}$ \\
\hline
\end{tabular}

\subsection{Evaluation Results of the Acceptability of Meat Analogue from Legumes}

The product was applied in Chopped Sizzling Milkfish (BangusSisig) to determine the acceptability of the product in terms of: appearance, aroma, texture, flavor or taste. A total of sixty (60) respondents participated in the evaluation of the product which was conducted at BulSU canteen. The rating scale used is Hedonic Scaling which has a rating scale of $1-9$.

As presented in Table 2, the appearance, aroma and texture got a mean score of 7 which is interpreted as like moderately based on the hedonic rating scaling. The taste or flavor attribute got a mean score of 8 which is interpreted as like very much and 7.35 for overall acceptability which is interpreted as like moderately

\subsection{Summary of Findings}

From the analysis of the data presented in the study, the following results are obtained:

1) Meat analogue from legumes was developed utilizing the combination of cannellini, lima and white kidney beans. The major procedures involved were: soaking, cooking, peeling, chopping, drying, layering and cutting.

2) Based on the microbiological analysis, the Aerobic Plate Count of the product has an actual value of less than $10^{4}$ cfus/g sample, the Psychotropic count accounts to less than $10^{3}$ cfus/g sample, the Coliform count with an actual value of less than $10^{2}$ cfus/g sample, Yeast and Molds count of less than 10 cfus/g sample, E. coli Count with an actual value of less than 10 cfus/g sample and a negative findings for Salmonella Determination.

3) In terms of acceptability of the product, the appearance, aroma and texture got a mean score of 7 which is interpreted as like moderately based on the hedonic rating scaling. The taste or flavor attribute got a mean score of 8 which is interpreted as like very much and 7.35 for overall acceptability which is interpreted as like moderately as well.

\section{Conclusions}

From the collated results of the study, the following conclusions were determined within the limitations and scope defined in the study:

1) The sample product passed the BFAD standards in terms of microbiological analysis.

2) The sample product passed the evaluation for overall acceptability specifically in terms of appearance, aroma, texture and taste or flavor. 
Table 2. Evaluation of the acceptability of meat analogue from legumes.

\begin{tabular}{|c|c|c|}
\hline CRITERIA & SCORE USING HEDONIC SCALING & RESULT \\
\hline Appearance & 7 & Like moderately \\
\hline Aroma & 7 & Like moderately \\
\hline Texture & 7 & Like moderately \\
\hline Taste/Flavor & 8 & Like very much \\
\hline Overall Acceptability & 7.35 & Like moderately \\
\hline \multicolumn{3}{|c|}{ RATING SCALE USED: HEDONIC SCALING } \\
\hline 9 & Like extremely & \\
\hline 8 & Like very much & \\
\hline 7 & Like moderately & \\
\hline 6 & Like slightly & \\
\hline 5 & Neither like nor dislike & \\
\hline 4 & Dislike slightly & \\
\hline 3 & Dislike moderately & \\
\hline 2 & Dislike very much & \\
\hline 1 & Dislike extremely & \\
\hline
\end{tabular}

\section{Recommendations}

In reference to the scope and delimitation, findings and conclusion of the study, the following recommendations are hereby presented:

1) Subsequent microbiological analyses of sample may be conducted to monitor microbiological quality of samples preferably within a 12-month period to comply with the standards set by the Department of Health.

2) Considering the diverse legume types, the future researchers can explore on testing the suitability of other beans and lentils like azuki, red beans and chickpeas to name a few. It can also be recommended to uncover the possibility of flavored meat analogues i.e. chicken or seafood flavored analogues.

3) Determination of appropriate packaging material of the product should be determined to maintain human consumption suitability, product safety and prolong its shelf-life.

4) Further experimentations and studies should be conducted to determine shelf-life and nutrient content analyses to complete regulatory requirements on food safety.

5) Further study should be conducted for the application of meat analogue in various food products.

\section{Acknowledgements}

The author would like to express her sincerest gratitude and appreciation to Ms. Melanie A. Caballero and Ms. Jhoane R. Cruz whose invaluable assistance and efforts made this research a reality.

\section{References}

[1] Food and Nutrition Magazine. (2013) Volume 3, July-August 2001 Issue.

[2] Cox, L.C. (2001) Health and Home Magazine. Volume 5, November 2001 Issue.

[3] http://www.fda.gov/Food/FoodScienceResearch/LaboratoryMethods 
Scientific Research Publishing (SCIRP) is one of the largest Open Access journal publishers. It is currently publishing more than 200 open access, online, peer-reviewed journals covering a wide range of academic disciplines. SCIRP serves the worldwide academic communities and contributes to the progress and application of science with its publication.

Other selected journals from SCIRP are listed as below. Submit your manuscript to us via either submit@scirp.org or Online Submission Portal.
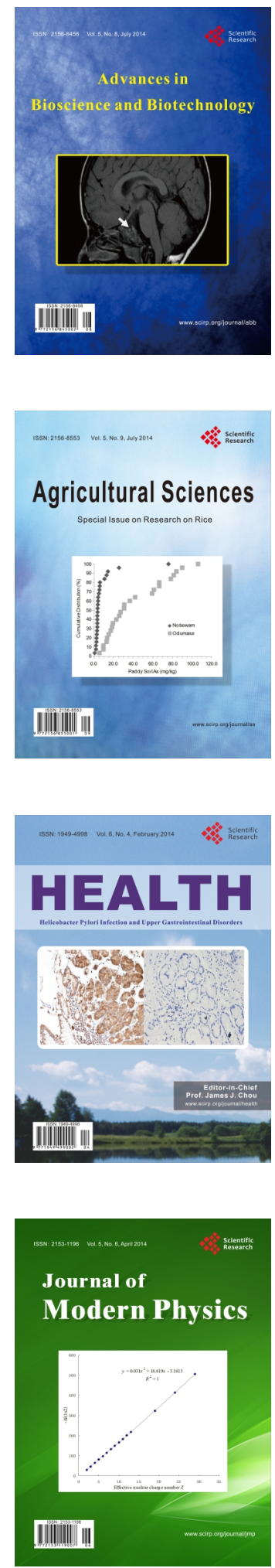
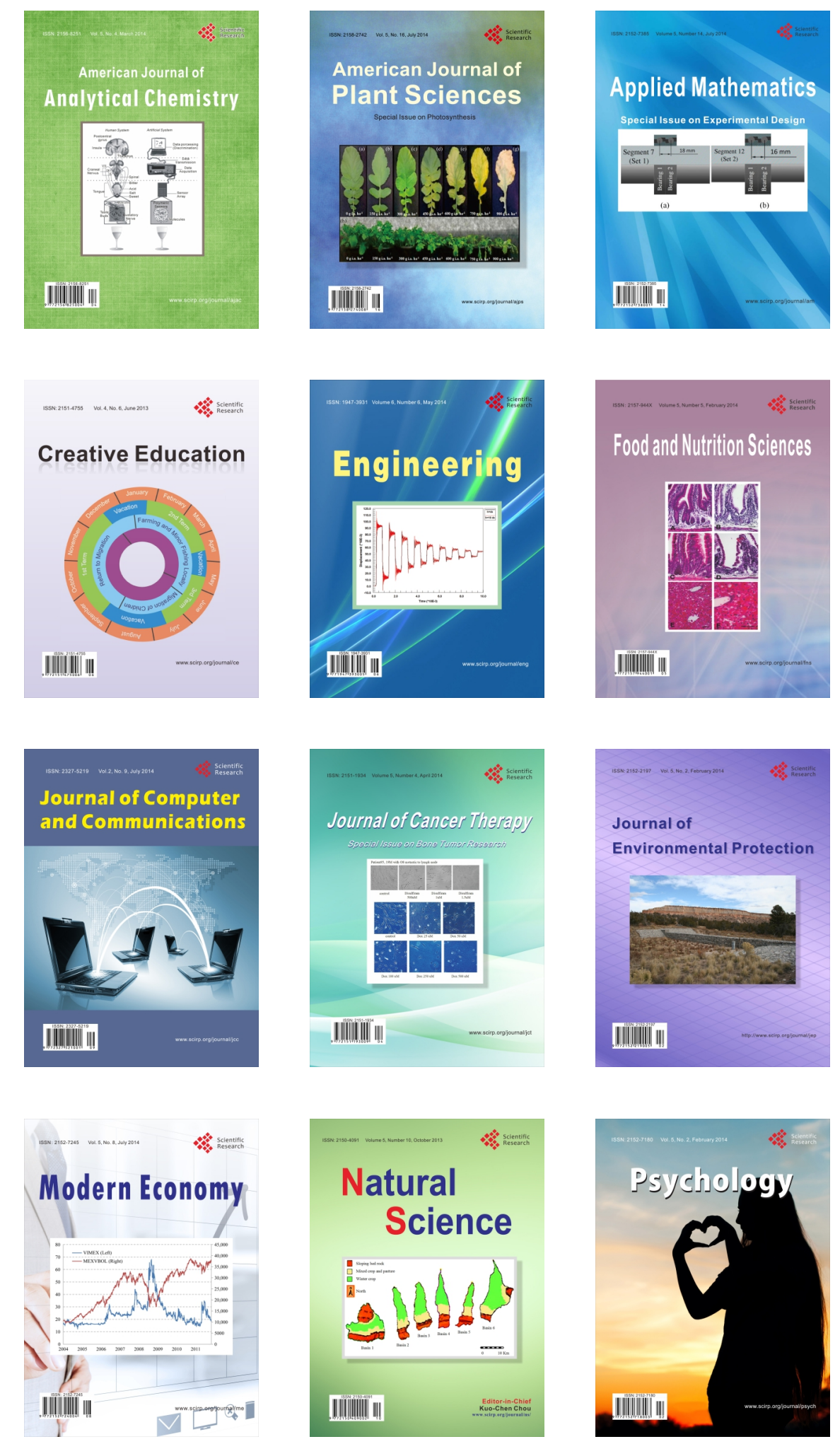